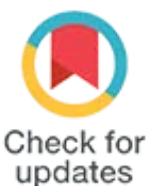

DOI: $10.29252 / \mathrm{ijcp}-27078$

\section{Correlation of Hematologic Indices with CT- pulmonary Arterial Obstruction Index in Patients with Acute Pulmonary Emboli}

\author{
Taraneh Faghihi Langhroudi ${ }^{1}$, Mahtab Borji Esfahani ${ }^{1}$, Isa Khaheshi ${ }^{2,}$, \\ Mohammadreza Naderian ${ }^{3}$, Farbod Zahedi Tajrishi ${ }^{4}$, Mohammad \\ Javad Namazi ${ }^{5}$ \\ ${ }^{1}$ Radiology Department, Modarres Hospital, Shahid Beheshti University of Medical \\ Sciences, Tehran, Iran \\ ${ }^{2}$ Cardiovascular Research Center, Shahid Beheshti University of Medical Sciences, \\ Tehran, Iran \\ 3 Cardiac Outcome Research and Education (CORE), Universal Scientific \\ Education and Research Network (USERN), Tehran, Iran \\ ${ }^{4}$ Faculty of Medicine, Babol University of Medical Sciences, Babol, Iran \\ ${ }^{5}$ Faculty of Medicine, Islamic Azad University, Tehran, Iran \\ * Corresponding author: Isa Khaheshi, Cardiovascular Research Center, Shahid \\ Beheshti University of Medical Sciences, Tehran, Iran. E-mail: \\ isa_khaheshi@yahoo.com
}

\begin{abstract}
Introduction: Acute Pulmonary thromboembolism (PTE) is an imperative medical condition with a considerable global impact. Inflammation is deemed to take a notable part in the pathophysiology of this potentially fatal disorder. The aim of the current study was to predict acute PTE severity in helical pulmonary CT-angiography using easily accessible hematological complete blood count ( $\mathrm{CBC}$ ) indices.

Methods: After exclusion of inflammatory conditions that may affect $\mathrm{CBC}$ parameters, a total of 69 consecutive patients with definite diagnosis of acute PTE according to pulmonary helical CT -angiography were recruited. Laboratory tests, including CBC parameters were performed on admission in the emergency unit, before initiation of any therapy. Neutrophil to lymphocyte ratio (NLR), platelet to lymphocyte ratio (PLR) and RDW to platelet ratio (RPR) were calculated in each case of acute PTE. Ultimately, $\mathrm{CT}$ pulmonary arterial obstruction index (PAOI) was assessed subsequent to pulmonary helical CT-angiography for each patient.

Results: We found that NLR is positively correlated with acute PTE severity according to CT pulmonary arterial obstruction index (PAOI) $(\mathrm{P}<0.01, \mathrm{r}=0.56)$; however, $\mathrm{PLR}$, RDW and RPR did not appear to show such correlations $(\mathrm{P}>0.05)$.

Conclusions: NLR could be an easily calculated and capable index to predict severity of acute PTE in pulmonary CT-angiography. Consequently, NLR might be used in precise risk stratification when suspicious for acute PTE and in accurately triage of patients who would benefit greatly from urgent diagnostic and therapeutic interventions.
\end{abstract}

\section{INTRODUCTION}

Pulmonary thromboembolism (PTE) is a widespread cardiovascular emergency with a notable mortality rate of $15 \%-20 \%$, irrespective of existing diagnostic and therapeutic modalities in the current years [1]. Increased white blood cells (WBCs) is supposed to be helpful as a prognostic and diagnostic marker for PTE. Activated leukocytes could generate free oxygen radicals, which lead to endothelial damage, thus, augmented inflammation and thrombogenesis [2]. Neutrophil to lymphocyte ratio (NLR) and platelet to 
lymphocyte ratio (PLR) have been shown to be related with many inflammatory disorders. These markers have been used as novel prognostic indicators for risk assessment of cancers and cardiovascular disease [3-6]. Moreover, the red cell distribution width (RDW) is a parameter that reveals the range of red cell sizes that are quantified within a sample. RDW and RDW to platelet ratio (RPR) are robustly related with prognosis in cardiopulmonary disorders [7-11].

During the previous years, the use of helical CT angiography has been remarkably increased in detection of acute PTE; furthermore, assessment of the degree of pulmonary obstruction, as CT pulmonary arterial obstruction index (PAOI), has been under-examined [12-14]. Regardless of recent and novel data regarding prognostic value of NLR, PLR, RDW and RPR in various clinical settings, the correlation of NLR, PLR, RDW and RPR with CT pulmonary arterial obstruction index (PAOI) in acute PTE has not been yet clearly determined.

The aim of the current study was to investigate the correlation of NLR, PLR and RDW with CT-PAOI in patients admitted with acute PTE.

\section{METHODS}

\section{Study Population}

This was a cross-sectional study including patients admitted to a tertiary hospital with diagnosis of acute PTE between January 2014 and February 2016. A total of 69 patients were confirmed to have PTE by helical CT angiography. The Institutional Review Board approved the study protocol and patients provided an informed written consent. Patients with known hematological, infectious and inflammatory disorders, as well as recent use of immunosuppressant drugs (including steroids) were excluded from the study.

\section{Hematologic Indices}

Blood samples were obtained on admission time in the emergency unit, before initiation of any therapy, to measure white blood cell (WBC) count, polymorphonuclear (PMN) cell count, lymphocyte cell count, platelet count, hematocrit and hemoglobin levels and red cell distribution width (RDW). Neutrophil to lymphocyte ratio (NLR), platelet to lymphocyte ratio (PLR) and RDW to platelet ratio (RPR) were calculated.

\section{CT Pulmonary Arterial Obstruction Index}

To describe CT obstruction index, the arterial tree of every lung was considered as having 10 segmental arteries (three to the upper lobes, two to the middle lobe and the lingula, and five to the lower lobes). Existence of an embolus in a segmental artery achieved 1 point and emboli in the most proximal arterial level were attained a score capable of the number of segmental arteries arising distally. To include further information about the residual perfusion distal to the embolus, a weighting factor was allocated to each value, according to the degree of vascular obstruction.

Table 1. Basic Demographic and Laboratory Information

\begin{tabular}{|c|c|}
\hline & Values \\
\hline Male sex & $40(58)$ \\
\hline Age (year) & $59.51 \pm 17.91$ \\
\hline Positive history of DM & $11(15.9)$ \\
\hline Positive history of HTN & $25(36.2)$ \\
\hline Positive history of HLP & $8(11.6)$ \\
\hline Smoking & $27(39.1)$ \\
\hline $\mathrm{WBC}\left(\times 10^{3} / \mathrm{mm}^{3}\right)$ & $9.37 \pm 3.62$ \\
\hline Neutrophil count $\left(\times 10^{3} / \mathrm{mm}^{3}\right)$ & $6.95 \pm 3.37$ \\
\hline Neutrophil percent & $71.97 \pm 10.03$ \\
\hline Lymphocyte count $\left(\times 10^{3} / \mathrm{mm}^{3}\right)$ & $1.76 \pm 0.72$ \\
\hline Lymphocyte percent & $20.31 \pm 8.85$ \\
\hline Hemoglobin (g/dL) & $12.32 \pm 2.38$ \\
\hline Hematocrit percent & $38.33 \pm 7.24$ \\
\hline Platelet count $\left(\times 10^{3} / \mathrm{mm}^{3}\right)$ & $217.49 \pm 77.07$ \\
\hline Creatinine $(\mathrm{mg} / \mathrm{dL})$ & $1.78 \pm 0.28$ \\
\hline Ejection fraction (\%) & $51.91 \pm 11.78$ \\
\hline Estimated SPAP $(\mathbf{m m H g})$ & $45.21 \pm 19.24$ \\
\hline \multicolumn{2}{|l|}{ TR in echocardiography } \\
\hline Mild & $33 \pm 47.83$ \\
\hline Moderate & $15 \pm 21.74$ \\
\hline Severe & $5 \pm 7.25$ \\
\hline \multicolumn{2}{|l|}{ RV dysfunction in echocardiography } \\
\hline Mild & $16(23.18)$ \\
\hline Moderate & $13(18.84)$ \\
\hline Severe & $4(5.80)$ \\
\hline \multicolumn{2}{|l|}{ Type of treatment } \\
\hline No treatment required & $2(2.90)$ \\
\hline $\mathrm{UFH}+$ warfarin & $34(49.37)$ \\
\hline Enoxaparin + warfarin & $27(39.13)$ \\
\hline Streptokinase & $1(1.45)$ \\
\hline Alteplase & $2(2.90)$ \\
\hline Reteplase & $1(1.45)$ \\
\hline Surgical removal of clot & $1(1.45)$ \\
\hline Alteplase + surgical removal of clot & $1(1.45)$ \\
\hline \multicolumn{2}{|c|}{ Data in table are presented as Mean \pm SD or No. $(\%)$} \\
\hline \multicolumn{2}{|c|}{$\begin{array}{l}\text { DM: diabetes mellitus; HLP: hyperlipidemia; HTN: hypertension; N: } \\
\text { number; RV: right ventricular; SD: standards deviation; SPAP: } \\
\text { systolic pulmonary arterial pressure; TR: tricuspid regurgitation; } \\
\text { UFH: unfractionated heparin }\end{array}$} \\
\hline
\end{tabular}

Table 2. Correlation between Hematological Indices and PTE Severity in Computed Tomography (CT) Angiography According to PTE Score

\begin{tabular}{lcc}
\hline & $\begin{array}{c}\text { Spearman's correlation } \\
\text { coefficient }(\boldsymbol{\rho})\end{array}$ & P value \\
$\begin{array}{l}\text { Neutrophil percent } \\
\text { Lymphocyte } \\
\text { percent }\end{array}$ & 0.55 & ${ }^{*}<0.01$ \\
PLR & -0.57 & ${ }^{*}<0.01$ \\
NLR & 0.17 & 0.16 \\
RDWPR & 0.56 & ${ }^{*}<0.01$ \\
\hline NLR: neutrophil to lymphocyte ration, PLR: platelet to lymphocyte
\end{tabular}
ratio; RDWPR: Red blood cell distribution width to platelet ratio

This factor was equal to zero when no thrombus was detected, one when moderately (partially) occlusive thrombus was diagnosed, or two with total obstruction. Accordingly, the highest CT obstruction index was 40 . Isolated sub-segmental embolus was regarded as a partially occluded segmental artery and allocated a value of 1 . The percentage of vascular obstruction was determined by dividing the patient score by the highest 
total score and by multiplying the product by $100[12-$ 14].

\section{Statistics}

Mean and standard deviation were used to describe quantitative variables, number and percentage for qualitative ones. The Kolmogorov-Smirnov test was used to define normal distribution. Spearman's test and scatter plots were used to determine the association between quantitative variables. A cut-off of 0.05 was set for significant correlation. All statistical analyses were performed using Stata/SE version 12.0 (Stata Corporation, College Station, TX).

\section{RESULTS}

Finally, 69 patients were enrolled in our study. Table 1 demonstrates all the basic demographic, laboratory and echocardiographic findings and type of treatment of the study. The study patients had a mean age of $59.51 \pm$ (17.91) years and mainly consisted of males (58\%). Trans-thoracic echocardiography was performed for all patients at admission. Severe RV dysfunction was detected in only $4(5.8 \%)$ of patients. Helical CT angiography was performed to measure the $\mathrm{CT}$ pulmonary arterial obstruction index (PAOI) which was $12.96 \pm 2.00$ for all patients. Sixty-six percent of patients had CT- PAOI less than 50\% which 33 percent had CTPAOI equal to or more than $50 \%$. Most patients underwent anticoagulant therapy either with UFH + warfarin $(52.17 \%)$ or enoxaparin + warfarin $(39.13 \%)$. The rest received alteplase, operative clot removal or alteplase + operative clot removal (8.7\%).

Table 2 indicates the correlation between neutrophil to lymphocyte ratio (NLR), platelet to lymphocyte ratio (PLR), RDW and RDW to platelet ratio (RPR) with CT-PAOI in patients with acute PTE. Among the measured hematological indices, we found that only $\operatorname{NLR}(\mathrm{P}<0.01, \mathrm{r}=0.56)$ was positively correlated to the severity of PTE according to CT-PAOI. However, PLR, RDW and RPR did not appear to show such correlations $(\mathrm{P}>0.05)$. Figure 1 depicts the positive correlation between NLR and CT-PAOI.

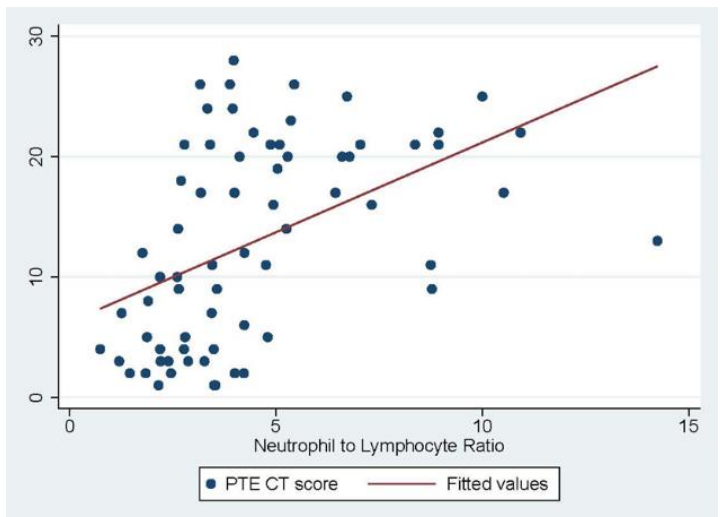

Figure 1. Scatter Plots Depicting Correlation between Neutrophil to Lymphocyte Ration to Pulmonary thromboembolism (PTE) Score in Computed Topography Angiography

\section{DISCUSSION}

Acute PTE is one of the most important cardiovascular conditions requiring immediate management causing considerable morbidity and mortality if not managed promptly. Regardless of advancements in diagnosis and treatment, mortality rate in patients with acute PTE remains high. A prompt evaluation of patients can help a great deal in further treatment steps. Accordingly, if proven to have a prognostic/diagnostic value, a variable such as NLR has a significant benefit since its quick to measure through a simple CBC. As widely accepted among physicians and healthcare professionals, a CBC is routinely used as initial assessment for most hospitalized patients.

In this study, our main goal was to determine whether the hematological indices NLR, PLR, RDW and RDWPR were correlated to PAOI in helical CT- scan and therefore, could be used as a prognostic factor in patients with acute pulmonary embolism. Several studies before ours had indicated the importance of these hematological indices in some acute cardiovascular conditions, including acute PTE. However, none of those studies assessed the correlation between these factors and PAOI.

NLR is one of the particular indices under research during the recent years. It is an indicator of a necessary harmony between neutrophils and lymphocytes that if disturbed, can be considered as a sign of higher cardiovascular mortality [15]. An example of studies regarding the prognostic role of NLR in cardiovascular conditions other than PTE is the one by Akdeniz and colleagues who investigated the long-term predictability of NLR in Pulmonary Arterial Hypertension and found positive results [16]. In 2017, Vakili et al. [17] introduced NLR and PLR as indexes that can be used for risk stratification of no-reflow phenomenon in patients with STEMI undergoing PPCI. The number of studies concerning the relationship between NLR and PTE is also growing. Kayrak et al. [18] assessed whether NLR could have a short-term prognostic value in acute PTE. They followed 359 patients with confirmed acute PTE who met their inclusion criteria and found that NLR can indeed have a predictive value in forecasting 30-day mortality of these patents. Furthermore, they reported a high negative predictive value $(93.9 \%)$ rather than a positive one (36.5\%). Ma et al. [19] also suggested that NLR could predict 30-day mortality in patients with PTE.

The results of our study confirm their results, while opening a new horizon for PTE evaluation. Our findings showed that NLR may be able to predict the severity of PTE and emphasized a considerable role for such a seemingly insignificant index. Therefore, NLR can be considered as a guide for clinical management and risk assessment of acute PTE. Also an increased NLR has a predictive role for PTE severity rather than a diagnostic role. 
Despite our study did not show a significant correlation between PLR, RDW RDWPR with CT-PAOI, these indices were described to be associated with numerous inflammatory and some cardiovascular disorders, including atherosclerosis, myocardial infarction and acute PTE $[9,20]$. PLR provides information about both aggregation and inflammatory pathways. For instance, as showed by Harun Kundi and his collogues [21], an elevated PLR is alone related with a high risk of mortality in patients with acute PTE. In view of the fact that both inflammation and endothelial injury take part in the pathogenesis of acute PTE, PLR can be a better marker in comparison with platelet or lymphocyte counts alone to predict mortality in patients with acute PTE.

RDW has been supposed as a prevailing predictor of mortality in a variety of conditions, including sepsis and septic shock, heart failure and acute myocardial infarction $[7,22,23]$. RDW has been independently associated with mortality in patients with pulmonary hypertension [9]. Moreover, RDW to platelet ratio (RPR) has been suggested to be a novel indicator of some inflammatory disorders and helpful in risk stratification and prediction of cardiovascular mortality in ST-elevation myocardial infarction [11,24].

One of the main distinctive characteristics of our study was development of a precisely thought-out and restricting set of inclusion criteria. By doing so, we excluded the role of a lot of comorbidities that might be present in the selected study population. The greatest limitation of our single-center study may be its relatively low sample size, which is of course due to our strict inclusion criteria. We encourage future multi-center studies with larger sample size considering the mentioned exclusion criteria.

In conclusion, NLR is a readily available, easy-to-assess parameter significantly correlated with PTE score on helical CT-angiography which makes it a valuable predictor of PTE severity. Therefore, this ratio may be used as part of a clinical risk stratification system to accurately evaluate the severity of PTE in the earlier stages of the disease.

\section{Conflict of Interest}

There is no conflict of interests with this article.

\section{REFERENCES}

1. Goldhaber SZ, Visani L, De Rosa M. Acute pulmonary embolism: clinical outcomes in the International Cooperative Pulmonary Embolism Registry (ICOPER). Lancet. 1999;353(9162):1386-9. doi: 10.1016/s0140-6736(98)075 34-5 pmid: 10227218

2. Zarbock A, Polanowska-Grabowska RK, Ley K. Plateletneutrophil-interactions: linking hemostasis and inflammation. Blood Rev. 2007;21(2):99-111. doi: 10.1016/j.blre.2006.06.0 01 pmid: 16987572

3. Cavus UY, Yildirim S, Sonmez E, Ertan C, Ozeke O. Prognostic value of neutrophil/lymphocyte ratio in patients with pulmonary embolism. Turk J Med Sci. 2014;44(1):50-5. doi: 10.3906/sag-1302-47 pmid: 25558558
4. Duffy BK, Gurm HS, Rajagopal V, Gupta R, Ellis SG, Bhatt DL. Usefulness of an elevated neutrophil to lymphocyte ratio in predicting long-term mortality after percutaneous coronary intervention. Am J Cardiol. 2006;97(7):993-6. doi: 10.1016/j.amjcard.2005.10.034 pmid: 16563903

5. Gary T, Pichler M, Belaj K, Hafner F, Gerger A, Froehlich H, et al. Platelet-to-lymphocyte ratio: a novel marker for critical limb ischemia in peripheral arterial occlusive disease patients. PLoS One. 2013;8(7):e67688. doi: 10.1371/journal.pone.0067688 pmid: 23844064

6. Kosumi K, Baba Y, Ishimoto T, Harada K, Nakamura K, Ohuchi $\mathrm{M}$, et al. Neutrophil/lymphocyte ratio predicts the prognosis in esophageal squamous cell carcinoma patients. Surg Today. 2016;46(4):405-13. doi: 10.1007/s00595-0151197-0 pmid: 26036223

7. Dabbah S, Hammerman H, Markiewicz W, Aronson D. Relation between red cell distribution width and clinical outcomes after acute myocardial infarction. Am J Cardiol. 2010;105(3):312-7. doi: 10.1016/j.amjcard.2009.09.027 pmid: 20102941

8. Fukuta H, Ohte N, Mukai S, Saeki T, Asada K, Wakami K, et al. Elevated plasma levels of B-type natriuretic Peptide but not Creactive protein are associated with higher red cell distribution width in patients with coronary artery disease. Int Heart J. 2009;50(3):301-12. doi: 10.1536/ihj.50.301 pmid: 19506334

9. Hampole CV, Mehrotra AK, Thenappan T, GombergMaitland M, Shah SJ. Usefulness of red cell distribution width as a prognostic marker in pulmonary hypertension. Am J Cardiol. 2009;104(6):868-72. doi: 10.1016/j.amjcard.2009.0 5.016 pmid: 19733726

10. Tonelli M, Sacks F, Arnold M, Moye L, Davis B, Pfeffer M, et al. Relation Between Red Blood Cell Distribution Width and Cardiovascular Event Rate in People With Coronary Disease. Circulation. 2008;117(2):163-8. doi: 10.1161/CIRCULATI ONAHA.107.727545 pmid: 18172029

11. Pusuroglu H, Cakmak HA, Akgul O, Erturk M, Surgit O, Akkaya E, et al. The prognostic value of admission red cell distribution width-to-platelet ratio in patients with STsegment elevation myocardial infarction undergoing primary percutaneous coronary intervention. Rev Port Cardiol. 2015;34(10):597-606. doi: 10.1016/j.repc.2015.03.014 pmid: 26387826

12. Ferretti GR, Collomb D, Ravey JN, Vanzetto G, Coulomb M, Bricault I. Severity assessment of acute pulmonary embolism: role of CT angiography. Semin Roentgenol. 2005;40(1):2532. doi: 10.1053 /j.ro.2004.09.004 pmid: 15732558

13. Mastora I, Remy-Jardin M, Masson P, Galland E, Delannoy V, Bauchart JJ, et al. Severity of acute pulmonary embolism: evaluation of a new spiral CT angiographic score in correlation with echocardiographic data. Eur Radiol. 2003;13(1):29-35. doi: 10.1007/s00330-002-1515-y pmid: 12541107

14. Qanadli SD, El Hajjam M, Vieillard-Baron A, Joseph T, Mesurolle B, Oliva VL, et al. New CT index to quantify arterial obstruction in pulmonary embolism: comparison with angiographic index and echocardiography. AJR Am J Roentgenol. 2001;176(6):1415-20. doi: 10.2214/ajr.17 6.6.1761415 pmid: 11373204

15. Cho KH, Jeong MH, Ahmed K, Hachinohe D, Choi HS, Chang SY, et al. Value of early risk stratification using hemoglobin level and neutrophil-to-lymphocyte ratio in patients with STelevation myocardial infarction undergoing primary percutaneous coronary intervention. Am J Cardiol. 2011;107(6):849-56. doi: 10.1016/j.amjcard.2010.10.067 pmid: 21247535

16. Ozpelit E, Akdeniz B, Ozpelit ME, Tas S, Bozkurt S, Tertemiz $\mathrm{KC}$, et al. Prognostic value of neutrophil-to-lymphocyte ratio in pulmonary arterial hypertension. J Int Med Res. 2015;43(5):661-71. doi: 10.1177/0300060515589394 pmid: 26347546

17. Vakili H, Shirazi M, Charkhkar M, Khaheshi I, Memaryan M, Naderian M. Correlation of platelet-to-lymphocyte ratio and neutrophil-to-lymphocyte ratio with thrombolysis in 
myocardial infarction frame count in ST-segment elevation myocardial infarction. Eur J Clin Invest. 2017;47(4):322-7. doi: $10.1111 /$ eci.12736 pmid: 28177528

18. Kayrak M, Erdogan HI, Solak Y, Akilli H, Gul EE, Yildirim O, et al. Prognostic value of neutrophil to lymphocyte ratio in patients with acute pulmonary embolism: a restrospective study. Heart Lung Circ. 2014;23(1):56-62. doi: 10.1016/j.hlc.2013.06.004 pmid: 23856365

19. Ma Y, Mao Y, He X, Sun Y, Huang S, Qiu J. The values of neutrophil to lymphocyte ratio and platelet to lymphocyte ratio in predicting 30 day mortality in patients with acute pulmonary embolism. BMC Cardiovasc Disord. 2016;16:123. doi: 10.1186/s12872-016-0304-5 pmid: 27259553

20. Celik A, Ozcan IT, Gundes A, Topuz M, Pektas I, Yesil E, et al. Usefulness of admission hematologic parameters as diagnostic tools in acute pulmonary embolism. Kaohsiung J Med Sci. 2015;31(3):145-9. doi: 10.1016/j.kjms.2014.12.004 pmid: 25744237

21. Kundi H, Balun A, Cicekcioglu H, Cetin M, Kiziltunc E, Cetin
$Z G$, et al. The relation between platelet-to-lymphocyte ratio and Pulmonary Embolism Severity Index in acute pulmonary embolism. Heart Lung. 2015;44(4):340-3. doi: 10.1016/j.hrtlng.2015.04.007 pmid: 25998993

22. Bazick HS, Chang D, Mahadevappa K, Gibbons FK, Christopher KB. Red cell distribution width and all-cause mortality in critically ill patients. Crit Care Med. 2011;39(8):1913-21. doi: 10.1097/CCM.0b013e31821b85c6 pmid: 21532476

23. Felker GM, Allen LA, Pocock SJ, Shaw LK, McMurray JJ, Pfeffer MA, et al. Red cell distribution width as a novel prognostic marker in heart failure: data from the CHARM Program and the Duke Databank. J Am Coll Cardiol. 2007;50(1):40-7. doi: 10.1016/j.jacc.2007.02.067 pmid: 17601544

24. Chen B, Ye B, Zhang J, Ying L, Chen Y. RDW to platelet ratio: a novel noninvasive index for predicting hepatic fibrosis and cirrhosis in chronic hepatitis B. PLoS One. 2013;8(7):e68780. doi: 10.1371 /journal.pone.0068780 pmid: 23874760 